\title{
Research on the Economic Impact of New Energy Fiscal and Tax Policies Based on CGE Model -- A Case from Inner Mongolia
}

\author{
HAN Weihong, PAN Lingling and YANG Xinjiletua ${ }^{1}$ \\ School of Economics and Management, Inner Mongolia University of Technology, Hohhot, China
}

\begin{abstract}
The development of new energy is not only an objective need for sustainable development of mankind, but also an important breakthrough for the world to foster new economic growth points. The focus of this article is on what kind of fiscal and tax policies the government implements can better guide the development of new energy and have a more favorable impact on the economy. This paper, taking wind power and solar photovoltaic power industries in the Inner Mongolia as an example, using the dynamic 3ED-CGE model, explored the economic impacts of different financial subsidies and preferential tax policies on new energy enterprises. And then this paper provided suggestions for the formulation of fiscal and tax policies. The study founded that compared with the fixed subsidy mechanism financial subsidies by the fall-off mechanism could be better to promote the growth of GDP, residents' welfare and employment. If the government didn't subsidize the new energy electric power's sales price to network after 2020, it would not have a negative impact. The $15 \%$ income tax rate was more effective in promoting the development of economic than $25 \% .8 .5 \%$ and $6 \%$ value-added tax rate exerted similar effects on the economy, but $6 \%$ value-added tax rate had a significant promotion on optimized adjustment the consumption structure of fossil energy and electric energy.
\end{abstract}

\section{Introduction}

The shortage of energy has been an important problem that plagued the economic development. With the further improvement of the level of industrialization, it is becoming more and more important to solve the problem of energy shortage. This will have a great impact on the economy and society of our country. The development and utilization of new energy have a great significance in effectively resolving the shortage of fossil energy resources, ensuring the growing energy demand [1], improving the ecological environment of the earth, promoting the sustainable economic development and optimizing the industrial structure. At present, the development of new energy industry is still in the primary stage. The government's fiscal subsidy and tax preferential policies on the new energy industry have become the key to reduce the cost of new energy generation, enhance the competitiveness of new energy generation industry and promote the scope of new energy development and utilization. In recent years, the development of China's new energy industry has made remarkable achievements. By the end of 2017, the new installed capacity of China's wind power is 15 million 30 thousand kilowatts, the accumulative installed capacity is 164 million kilowatts, the new installed capacity of solar photovoltaic power generation is 34 million 540 thousand $\mathrm{KW}$ and the accumulative installed capacity is 130 million kilowatts. The cumulative installed capacity of solar photovoltaic and wind power is the world's first.

As a resource area, the Inner Mongolia Autonomous Region has rich solar energy and wind energy by virtues of its unique natural conditions. In China, the solar radiation in Inner Mongolia is only second to Tibet, and the wind energy reserves in the whole region account for $1 / 5$ of the total wind energy reserves in the country and therefore Inner Mongolia has great potential for the development of new energy industry. As an important means to guide the economic operation and adjust the industrial structure, fiscal and taxation policies have a significant impact on economic efficiency. Therefore, this paper, taking the Inner Mongolia Autonomous Region wind power and solar photovoltaic power generation industries as an example, studies the influences of different financial subsidies and tax preferences on the economic. And on this basis, it seeks to the appropriate new energy finance and taxation policy to develop the new energy industry, boost economic growth, increase the welfare of the residents, and realize the target of the development of renewable energy development" in 13th Five-Year", "By 2020, the electricity price of the wind power project can compete with the local coal-fired power generation platform, and the PV item price can be equivalent to the electricity price of the power grid." This is also a pressing problem for local and central governments.

Entering the twenty-first Century, China's new energy industry has begun to grow rapidly. China's research on 
new energy industry is endless. Firstly, the theoretical analysis shows that the expansion of the new energy development fund ${ }^{[2]}$, the improvement of the new energy price policy and the adjustment mechanism $\left.{ }^{[3}\right]$, the use of incentive tax preferential policy in the development stage of the new energy industry ${ }^{[4]}$, and the construction of the tax system of the new energy industry all can improve the quality of the tax ${ }^{[5]}$. Secondly, the research on fiscal and taxation policies to promote the development of new energy industry is concentrated on the following aspects, (1) With regard to the policy of financial subsidies, through the full summary of our new energy and tax policy, Y. Wang (2008) pointed out that the new energy and tax policy is not appropriate, but the "output subsidy" can improve the competitiveness of new energy and promote the development of new energy industry ${ }^{[6]}$. J. Kaldellis (2002) analyses the role of the U. S. wind power generation price policy in promoting the development of the new energy industry, and he believed that the Feed-in tariff has a positive role in promoting the further development of the industry ${ }^{[7]}$. (2) With regard to the policy of tax preferences, Q. Liu (2013) and J. Ma (2015) made a comprehensive evaluation of panel data of new energy listed companies by regression analysis and multi-level fuzzy optimization model, then they proved that the tax preferential policies have great impact on the development of the company, and gave a positive answer to the good effect of tax policy ${ }^{[8][9]}$.

Finally, the influence of financial subsidies on the economy is mainly studied on the influence of the wind energy fiscal and tax policies on the economic operation. The research shows that the fiscal policy to promote the development of wind energy industry also increases the total output value, he total profit and tax, and the employment number of the other energy and electricity industries. In addition, the new energy industry has a wide industrial chain and high technical content, which makes the government support the new energy industry in the process of development and will realize the agglomeration economic effect of this industry ${ }^{[10]}$. Y. Sun (2012)taken single state static model, CGE-LHR model, to study the impacts of traditional energy tax and wind power subsidies on the development of China's wind power industry and the macroeconomic [11], but this study can neither examine the tax policy of the wind power industry, nor can simulate the economic changes in many period.

What are the effects of the new energy policies on the regional economy, especially in Inner Mongolia and other areas with unique energy characteristics, and how to use appropriate fiscal and tax policies to promote the optimization and upgrading of energy consumption structure? There is no quantitative analysis at present. In view of the shortcomings of the exited research, this paper takes the wind power and solar photovoltaic power industry in Inner Mongolia as an example. Considering the specific natural conditions and economic conditions of the Inner Mongolia Autonomous Region, we can calculate the general equilibrium model of the regional energy environment, 3ED-CGE model ${ }^{[12]}$, and set up 5 scenario simulation schemes. And we compared and analyzed the effects of different financial subsidies and preferential tax policies on the GDP, the level of employment, the welfare of the residents, the traditional power sector, the new energy power sector and the fossil energy sector, and then provided some policy suggestions. We tried to make up for the new energy fiscal and taxation policy regional economic impacts empirical analysis blank.

\section{Analysis of the impacts of new energy finance and taxation policies on the economy}

This paper used the CGE model to study the impacts of the implementation of new energy fiscal and tax policies on the economy. In order to understand the relationship between policy implementation and economic operation, before building the model, the influence mechanism of new energy fiscal and tax policies on the economy is analyzed in advance.

\subsection{Analysis of the influence of economic growth}

Implementing fiscal and tax preferential policies for new energy power generation enterprises, on the one hand, it is beneficial to reduce the production cost of new energy generation enterprises, improve their market competitiveness, and provide higher profit space for this kind of enterprises to expand reproduction. On the other hand, it will also reduce the production costs of enterprises using electricity for production and then reduce the cost of production. The price of these enterprises stimulates the increase of their demands, thus it can promote the economic benefits of these enterprises. Based on the above two points, the implementation of fiscal and taxation policies will help promote economic growth. However, under the assumption of certain conditions of government financial subsidies, the increase of financial subsidies to new energy power generation enterprises will reduce the financial support of other enterprises. Compared with traditional mature industries, the new energy industry is a new industry, and its output efficiency is much lower than that of traditional industries. The economic growth point in Inner Mongolia is mainly concentrated in the traditional mature heavy industry. Therefore, the increase of new energy financial subsidies will have a certain negative impact on the economic growth. According to the relationship between "Okun's law" and W. Liu, et al (2015) ${ }^{[13]}$, we can see that the stable growth of economy and the increase of employment rate are have closely relationship. Fiscal and taxation policies that can promote economic growth will also help increase employment. In addition, since 2010, China has promoted the rapid improvement of the level of welfare transformation, and the coupling degree of economic growth and welfare transformation have also increased (J. Wu, 2015) ${ }^{[14]}$. Therefore, the new energy finance and taxation policy will also have a certain impact on the welfare of residents.

\subsection{Analysis of the impacts of power sector output}




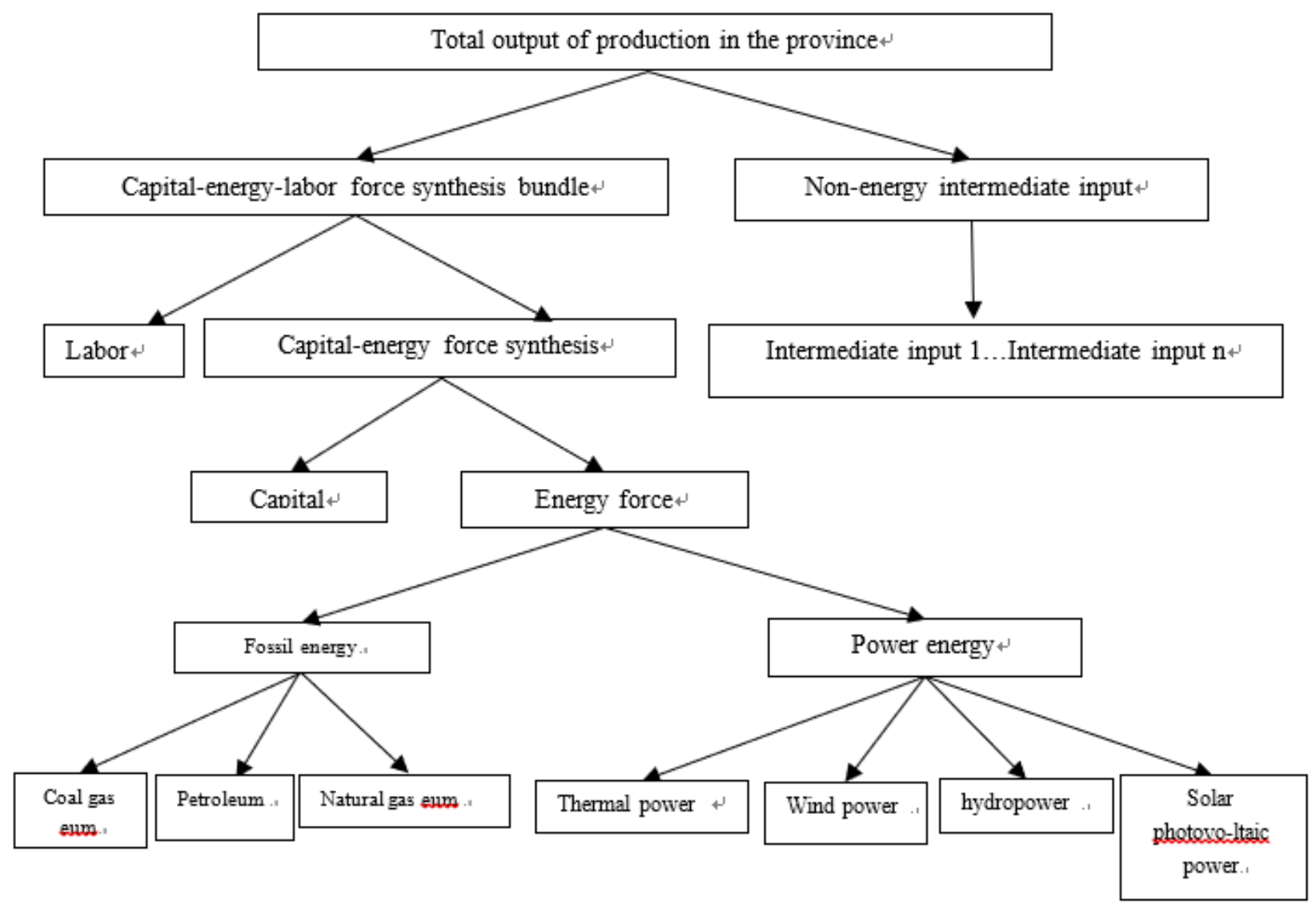

Figure 2. Production Structure Hierarchy Diagram

In this paper, the production factors of new energy power enterprises can be classified into two types: labor force and capital. As shown in figure 1, the horizontal axis L represents labor, and the longitudinal axis $\mathrm{K}$ represents capital. Under the fixed input conditions, the equivalent cost curves of the new energy power generation enterprise are $C_{1}$ and $C_{2}$, and the corresponding maximum output curves are Q1 and Q2, E1 and E2 represent the equal cost curves, E1 and E2 are optimal allocation points.

$$
P_{K} \cdot K+P_{L} \cdot L=C_{1}
$$

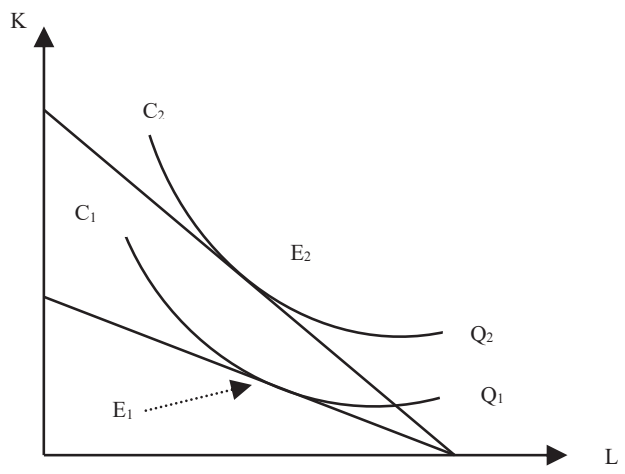

Figure 1. Effect Analysis in Output of New Energy Fiscal and Taxation Policies

This paper assumes that the government's preferential policies for new energy power enterprises will not affect the amount of labor input, but it will reduce the use price of unit capital. Under the condition of a certain capital input, the amount of capital input will increase, so the corresponding output curve will change from $\mathrm{Q}_{1}$ to $\mathrm{Q}_{2}$, and the optimal allocation point will also change from $E_{1}$ to $E_{2}$. From the figure 1, it is obvious that the output of $E_{2}$ is higher than $E_{1}$, so the output of new energy power enterprises will increase, this means the implementation of new energy and tax policies will have a positive impact on the increase of new energy sector output. The output of the traditional power sector will be reduced when the total demand for electricity remains unchanged.

\section{Building model and data sources}

\subsection{Building model}

The model includes three kinds of production factors, they are labor, capital and depreciation; and five kinds of enterprises, they are thermal power enterprises, hydroelectric power enterprises, wind power enterprises, solar power enterprises and general enterprises. In order to achieve the purpose of the study, the power sector is divided into thermal power sector, hydropower sector, wind power sector and solar photovoltaic power generation sector. The main modules in the model are production module, trade 
module, income and expenditure module, and investment saving module.

\subsubsection{Production module}

In the 3ED-CGE model, it is assumed that every production department exists as a competitive enterprise and every production department can produce only one commodity or service, and the scale of each enterprise remains unchanged. In the production module, the CGE model uses a multi-layer nested constant replacement elasticity (CES) production function to describe the different alternatives between different production factors. The production structure is divided into five levels.

According to the structure of the CES production function, the synthetic energy beam of electric energy is decomposed into thermal power, wind power, hydropower and photovoltaic power. The specific decomposition equations are as follows:

The equation (2) described the electric force energy synthetic bundle $\left(Q E L D_{i}\right)$, which is composed by thermal power $\left(Q T H D_{i}\right)$, wind power $\left(Q W D_{i}\right)$, hydropower $\left(Q H Y D_{i}\right)$ and solar energy $\left(Q S O D_{i}\right)$. And according to the structure of the CES production function, the equation (3) to (5) represent the relative price function of the two input elements (the first order condition of the CES production function) to determine the optimal input combination, and the equation (6) is the constraint bar for the production departments to maximize the profit.

$$
\begin{gathered}
Q E L D_{i}=A_{i}^{e l}\left[\alpha_{i}^{t h} Q T H D_{i}^{\rho_{i}^{t w h s}}+\alpha_{i}^{w} Q W I D_{i}^{\rho_{i}^{t w h s}}+\right. \\
\alpha_{i}^{h} Q H Y D_{i}^{\rho_{i}^{t w h s}}\left(1-\alpha_{i}^{t h}-\alpha_{i}^{w}-\right. \\
\left.\left.\alpha_{i}^{q}\right) Q S O D_{i}^{\rho_{i}^{t w h s}}\right]^{\frac{1}{\rho_{i}^{t w h}}} \\
\frac{P T H D_{i}}{P W I D_{i}}=\frac{\alpha_{i}^{t h}}{\alpha_{i}^{w}}\left(\frac{Q W I D_{i}}{Q T H D_{i}}\right)^{1-\rho_{i}^{t w h s}} \\
\frac{P W I D_{i}}{P H Y D_{i}}=\frac{\alpha_{i}^{w}}{\alpha_{i}^{h}}\left(\frac{Q H Y D_{i}}{Q W I D_{i}}\right)^{1-\rho_{i}^{t w h s}} \\
\frac{P_{Y Y D_{i}}}{\operatorname{PSOD}_{i}}=\frac{\alpha_{i}^{q k}}{\left(1-\alpha_{i}^{t h}-\alpha_{i}^{w}-\alpha_{i}^{h}\right)}\left(\frac{Q S O D_{i}}{Q H Y D_{i}}\right)^{1-\rho_{i}^{t w h s}} \\
\operatorname{PELD}_{i} \cdot Q E L D_{i} \\
=P T H D_{i} \cdot Q T H D_{i}+P W I D_{i} \cdot Q W I D_{i} \\
+P H Y D_{i} \cdot Q H Y D_{i}+P S O D_{i} \cdot Q S O D_{i}
\end{gathered}
$$

\subsubsection{Trade module}

The electric power produced in the Inner Mongolia region, in addition to its own use, is also transported to North China, Northeast, Mongolia and other regions and countries, and the power does not to be transferred into and imported to the province (as shown in figure 3). Thus in this module, the electricity produced

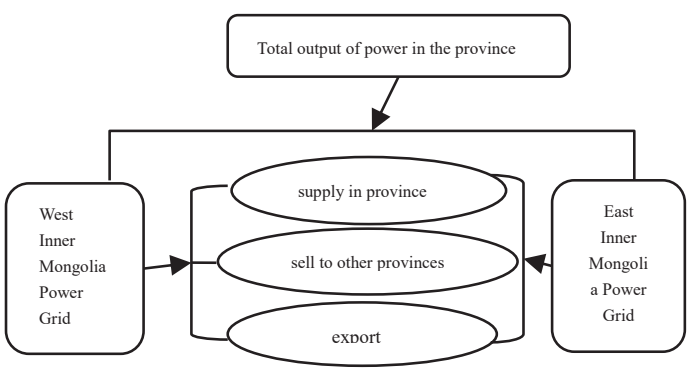

Figure 3. Inner Mongolia electric power trade chart

in the province is composed of three parts: supply in province, sell to other provinces, and export, and this is described by the constant transformation elasticity (CET) function.

\subsubsection{Income and expenditure module}

$Y E N T A=\sum_{i} P K_{i} \cdot s_{i j f_{\text {ent }}} \cdot Q K D_{i}+\overline{\text { transf }_{\text {ent } 1 \text { gov }}}+\overline{\text { transffrentcoov }}$

The equation (7) defines that the income of the new energy enterprise (YENTA )mainly comes from the capital reture $\left(\sum_{i} P K_{i} \cdot\right.$ shif $\left._{\text {ent }} \cdot Q K D_{i}\right)$ and the local government ( $\overline{\text { transfrent } \lg o v}$ ) and the central government ( $\overline{\text { transfrentcgov }}$ ) for the transfer payment of the enterprise.

$$
E E N T A=\overline{\text { transf } r_{\text {hent }}}+C I N T+\tau^{\text {ent }} \cdot Y E N T
$$

Equation (8) represents enterprise expenditure ( EENTA ) including transfer payment to residents, enterprise income tax (CINT) and other related taxes and fees $\left(\tau^{\text {ent }} \cdot Y E N T\right)$.

\subsubsection{Investment saving module}

In the Keynes equilibrium state, the willingness of enterprises to invest is equal to savings. Therefore, the module design is as follows:

$$
\begin{gathered}
P K_{i}=\sum_{j} b_{i j} P C_{j} \\
I D_{i}=\sum_{j} b_{i j} \overline{D K_{j}} \\
D E P R=\sum_{i} \delta_{i} \cdot P K_{i} \cdot Q K D_{i}
\end{gathered}
$$

The equation (9) describes that the capital investment price of each department is determined by the product price and the capital investment coefficient matrix $\left(\sum_{j} b_{i j}=1\right)$. The equation (10) describes the capital investment demand $\left(I D_{i}\right)$, which is determined by the product of the capital

Investment $\left(D K_{j}\right)$ and the capital investment 
coefficient matrix of each department $\left(\sum_{i} b_{i j}=1\right)$; the equation (11) describes the depreciation of capital is determined by the capital prices $\left(P K_{i}\right)$, capital demand quantities $\left(Q K D_{i}\right)$ and capital depreciation coefficient $\left(\delta_{i}\right)$.

$$
S A V=(H C S A V+H R S A V)+(L G S A V+C G S A V)
$$

The equation (12) indicates that the total savings ( $S A V$ ) is the government savings (the sum of local government savings and the central government savings) and residents' savings (the sum of urban and rural residents' savings).

$$
I D_{i}=S A V
$$

Equation (13) indicates that capital investment demands equal to total savings.

\subsection{Data source and program test}

When determining the elasticity of substitution of the model, the characteristics of Inner Mongolia's economy are needed to be taken into account ${ }^{[15][16]}$. Because the substitution elasticity rate has great influence on the situation simulation results, the sensitivity test is carried out in this paper. On the basis of the base period value, the simulation results are calculated and obtained after the increase or decrease in proportion. The analysis results show that the model is stable and the simulation results are credible. The impacts of the reasonable range on the simulation results are not significant, so the simulation results are credible. On the basis of the above sensitivity tests, consistency and homogeneity tests were carried out before running the GAMS program. First, the consistency check refers to whether the relevant data in the base period SAM are calibrated for the CGE parameter, and whether the solution obtained by the Walras variable is zero to predict the base period is the same as the value of the base period SAM; second, the price homogeneous test, if a set of price vectors is the solution of the equation group, then the vector of any positive multiple vectors of this vector is the same. The solution of the model accords with the condition of zero order price of CGE model. The above tests ensure the correctness and scientificalness of the model.

\section{Scenario simulation and result analysis}

\subsection{Designing scenario scheme}

The financial subsidies to the new energy generation enterprises are concentrated in the operation of the power plant, and in this link the policies are standardized, sustainable, easy to quantify, and the subsidies in the operation of the power plant have direct impact on the life of the residents and the production of the enterprises. Therefore, the research objects are finance and taxation policies in the operation stage of new energy generation enterprises.

Combining with the existing financial and tax policies and new energy development targets in Inner Mongolia, we compared the effects of different financial subsidies and tax rates on the economy. The specific content are shown in Table 1.

\begin{tabular}{|c|c|c|}
\hline Scenario & \multicolumn{2}{|c|}{ Scenario contents } \\
\hline $\begin{array}{c}\text { Scenario } \\
1\end{array}$ & $\begin{array}{l}\text { From } 2018, \mathrm{PV} \text { and wind } \\
\text { subsidies will be reduced by } \\
0.1333 \text { yuan } / \mathrm{kwh} \text { and } 0.0616 \\
\text { yuan / kwh per annum } \\
\text { respectively, and the subsidy } \\
\text { will reach } 0 \text { by } 2020 \text {. }\end{array}$ & $\begin{array}{l}\text { From } 2018 \text { to } 2020 \text {, the income } \\
\text { tax rate is } 15 \% \text {; from } 2021 \text { to } \\
2030 \text {, the income tax rate is } 25 \% \text {. } \\
\text { From } 2018 \text { to } 2030 \text {, the value } \\
\text { added tax rate is } 8.5 \% \text {. }\end{array}$ \\
\hline $\begin{array}{c}\text { Scenario } \\
2\end{array}$ & $\begin{array}{l}\text { From } 2018, \mathrm{PV} \text { and wind } \\
\text { subsidies will be reduced by } \\
0.0753 \text { yuan } / \mathrm{kwh} \text { and } 0.0336 \\
\text { yuan / kwh per annum } \\
\text { respectively, and the subsidy } \\
\text { will reach } 0 \text { by } 2030 \text {. }\end{array}$ & $\begin{array}{l}\text { From } 2018 \text { to } 2020 \text {, the income } \\
\text { tax rate is } 15 \% \text {; from } 2021 \text { to } \\
2030 \text {, the income tax rate is } 25 \% \text {. } \\
\text { From } 2018 \text { to } 2030 \text {, the value } \\
\text { added tax rate is } 8.5 \% \text {. }\end{array}$ \\
\hline $\begin{array}{c}\text { Scenario } \\
3\end{array}$ & $\begin{array}{l}\text { From } 2018 \text { to } 2030 \text {, the } \\
\text { on-grid tariff subsidies are the } \\
\text { same as in } 2017 \text {. }\end{array}$ & $\begin{array}{l}\text { From } 2018 \text { to } 2030 \text {, the income } \\
\text { tax rate is } 15 \% \text {. } \\
\text { From } 2018 \text { to } 2030 \text {, the value } \\
\text { added tax rate is } 8.5 \% \text {. }\end{array}$ \\
\hline $\begin{array}{c}\text { Scenario } \\
4\end{array}$ & $\begin{array}{l}\text { From } 2018 \text { to } 2030 \text {, the } \\
\text { on-grid tariff subsidies are the } \\
\text { same as in } 2017 \text {. }\end{array}$ & $\begin{array}{l}\text { From } 2018 \text { to } 2020 \text {, the income } \\
\text { tax rate is } 15 \% \text {; from } 2021 \text { to } \\
2030 \text {, the income tax rate is } 25 \% \text {. } \\
\text { From } 2018 \text { to } 2030 \text {, the value } \\
\text { added tax rate is } 6 \% \text {. }\end{array}$ \\
\hline $\begin{array}{c}\text { Scenario } \\
5\end{array}$ & $\begin{array}{l}\text { From } 2018 \text { to } 2030 \text {, the } \\
\text { on-grid tariff subsidies are the } \\
\text { same as in } 2017 \text {. }\end{array}$ & $\begin{array}{l}\text { From } 2018 \text { to } 2020 \text {, the income } \\
\text { tax rate is } 15 \% \text {; from } 2021 \text { to } \\
2030 \text {, the income tax rate is } 25 \% \text {. } \\
\text { From } 2018 \text { to } 2030 \text {, the value } \\
\text { added tax rate is } 8.5 \% \text {. }\end{array}$ \\
\hline
\end{tabular}

Table 1. Scenario schemes

\subsection{The analysis of simulation results}

In order to accurately describe the impacts of each scenario the simulation results of scenario 1 to 5 are respectively subtracted from the baseline scenario simulation results, and then the impacts of each scenario on the economy of the Inner Mongolia are analyzed.

\subsubsection{The impacts on the macro-economy}

The implementation of the new energy financial subsidies and tax policy can affect the various aspects of the regional economic system. This article mainly studied from the GDP, rate of employment and residents' welfare.

(1) The impacts on GDP 


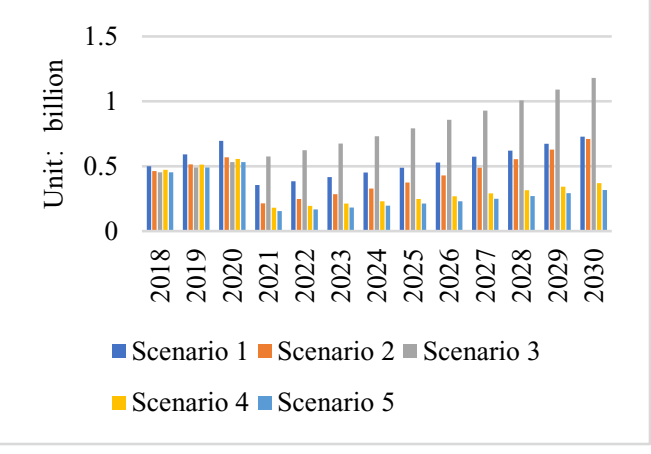

Figure 4. Changes in Real GDP

From figure 4, we could see that the financial subsidies and tax policies of different schemes had different effects on GDP. From the aspect of financial subsidies, before 2020, scenario 1 was more effective than scenario 2 and 5 in promoting the growth of GDP. New energy as a new industry, the reduction of subsidy could increase GDP. As time goes on, compared with scenario 5, the promotion effect of scenario 1 and 2 was more and more obvious. This showed that the development of the new energy industry was gradually becoming mature, and the implementation of the slope subsidy mechanism could promote the healthy development of the economy. This is due to the appropriate subsidies can promote the healthy development of the industry. In the stage of industrial formation, the support of the government increased the competitiveness of enterprises. When the industry has developed to a mature stage, the government should gradually withdraw from the market and release the vitality of the market. This not only improved the efficiency of financial capital, but also promoted further economic growth. From the aspect of tax policies, the reduction of income tax had a positive impact on GDP. In the long term, compared with the $25 \%$ income tax rate of scenario 4 , the tax rate dropped to $15 \%$ of the scenario 3 promoted GDP more significant. The substantial reduction of the income tax rate greatly reduced the cost of new energy power generation, and the electricity price decreased accordingly, thus the production department could reduce the electricity consumption cost. The added value of the second industry in Inner Mongolia accounted for about $50 \%$ of the gross domestic product. Low electricity price provided a strong condition to promote the production sector's output, which would promote faster growth of the economy. By contrasting scenario 4 and $5,8.5 \%$ and $6 \%$ of the VAT rate had a relatively close impact on GDP. This was probably because the new energy power generation enterprises' wind, light and other raw materials had no entry deduction that made the actual value added tax still higher, so the effect of reducing the value-added tax rate by $2.5 \%$ had a small impact on GDP.

(2)The impacts on the employment rate

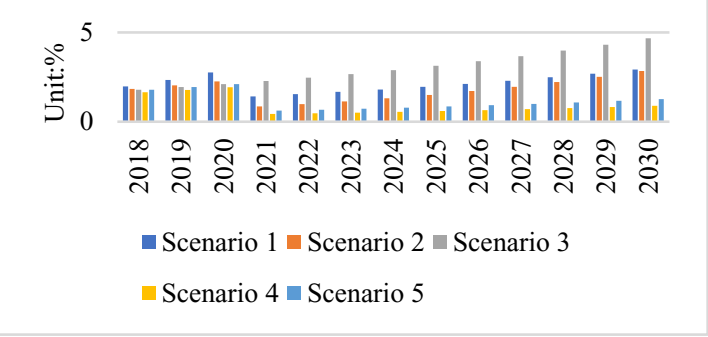

Figure 5. Changes in the Employment Rate

The new energy finance and taxation policy had a similar impact on the employment rate to GDP. From the aspect of financial subsidies, in the short term, in the scenario 3 the investment and construction of new energy power generation enterprises were more active, which had led to higher labor demand. But in the long run, the higher and fixed subsidy was less than the backslide subsidy in labor demand. From the aspect of tax policies. In scenario 3 , the $15 \%$ income tax rate in 2018-2030 years played a significant role in promoting employment. However, after the value added tax rate was reduced from $8.5 \%$ to $6 \%$, the employment rate declined over time. The possible reason is that the reduction of value-added tax encourages the

(3)The impacts of the welfare of the residents

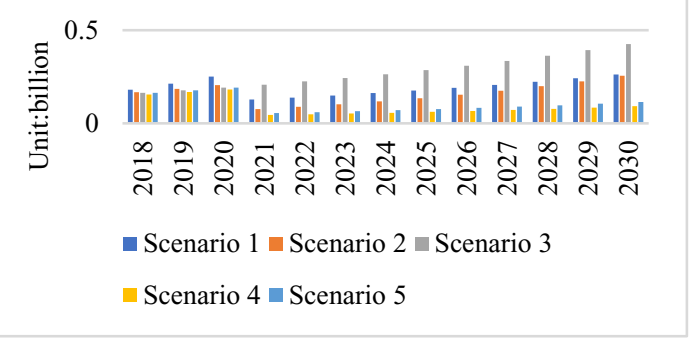

Figure 6. Changes in Urban residents' welfare

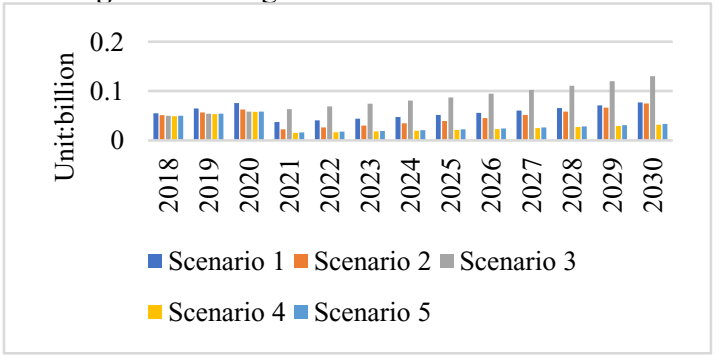

Figure 7. Changes in rural residents' welfare

output of new energy power. In the case of constant power demand, new energy power produces a substitute for traditional power. As the demand for new generation of power generation is far lower than that of thermal power generation, the employment rate of residents in the whole region is decreasing.

This paper took residents' consumption demand as an indicator of residents' welfare. The result of the scenario simulation was shown in figure 6 and figure 7. In terms of financial subsidies, the implementation of scenario 1 and 2 with back slope mechanism enhanced the demand level of residents. The reduction of financial expenditure 
for new energy enterprises would increase transfer payments to residents and other industries, so the demand level of residents may be improved. In terms of taxation, figure 6 and figure 7 shown that the lower the income tax, the higher the residents' welfare. These figures also shown the lower the VAT, the lower the welfare of the urban residents and the rural residents. Further more, the decline of urban residents' welfare was more obvious.

\subsubsection{The impacts on traditional power and new energy power output}

The fiscal and tax policies promoted the output of

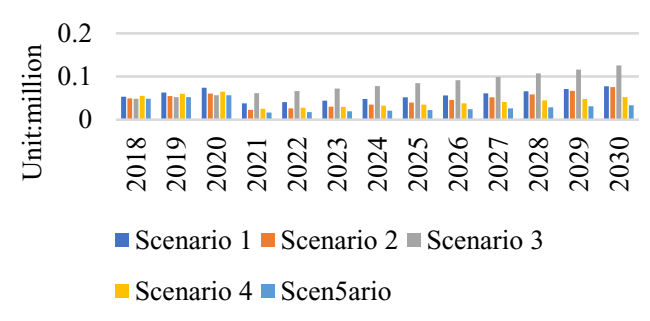

Figure 8. Changes in Output of Hydroelectric Power

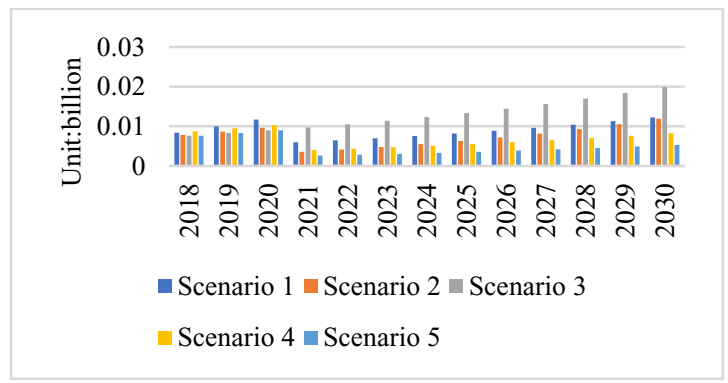

Figure 9. Changes in Output of Thermal Power

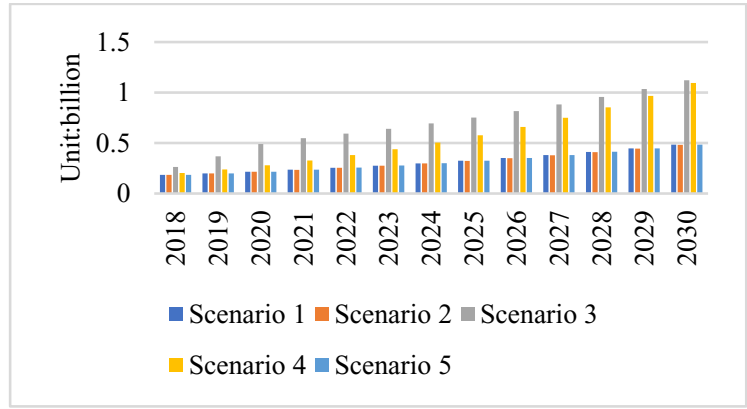

Figure 10. Changes in Output of Wind Power

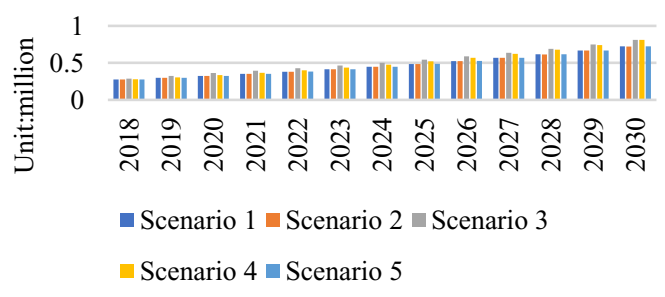

Figure 11. Changes in Output of Photovoltaic Power

new energy power and traditional power, but the promotion of the former was much higher than that of the latter. In terms of financial subsidies, the incentive effect of scenario 1 and 2 for all kinds of electricity generation enterprises was better than scenario 5 . Therefore, after 2020, the implementation of the new energy power zero subsidy policy could not only save financial funds, but also had no negative impact on the development of new energy power industry. Government support gradually reduced to zero subsidy not only could enhance the competitiveness of new energy enterprises, but also improved the marginal utility of financial funds. Before 2030, the promotion of the two subsidies to the electricity output of new energy was higher than that of the traditional power, and the proportion of new energy in electricity energy was rising. It showed that the new energy power output under two subsidy policies occupied an absolute advantage. Among them, scenario 1 was the best way to promote the output of new energy. In terms of taxation, figure 10 and figure 11 shown that the lower the income tax and VAT rate, the higher the output of new energy power. After 2020, maintaining $15 \%$ of the income tax rate led to the new energy output to increase effectively. If $25 \%$ of the income tax rate was implemented after 2020, the electricity output could decline significantly. In the long term, the fiscal and tax policy of scenario 3 was beneficial to maintain the higher level of traditional and new energy power output. When the tax rate of VAT reduced from 8.5 to $6 \%$, the promotion effect of the electricity output was gradually reduced, but the effect on the output of new energy electricity was far greater than that of the traditional power, which made the consumption of new energy increase significantly. This meant this policy optimized the structure of electricity and energy demand.

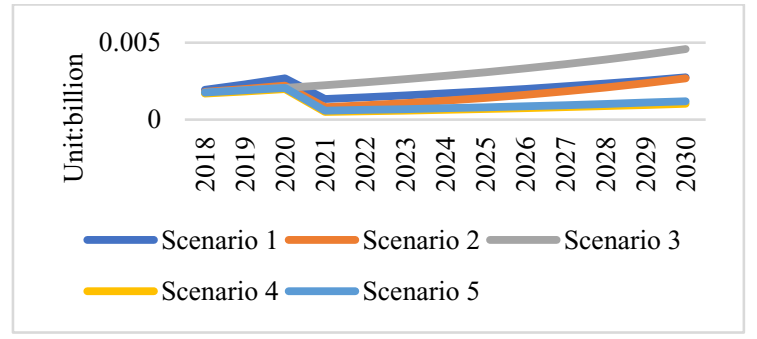

Figure 12. Changes in Output of Gas

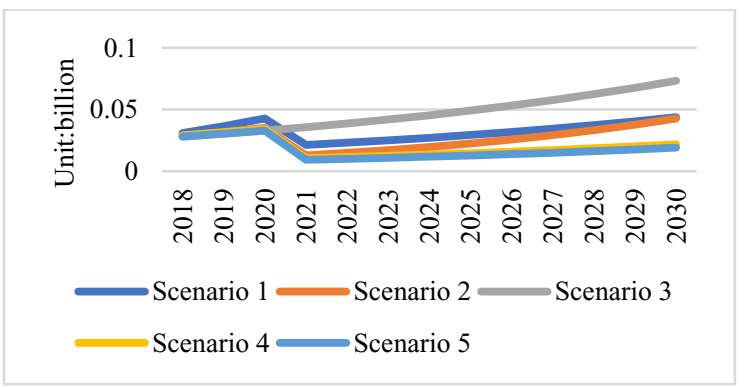

Figure 13. Changes in Output of Coal 


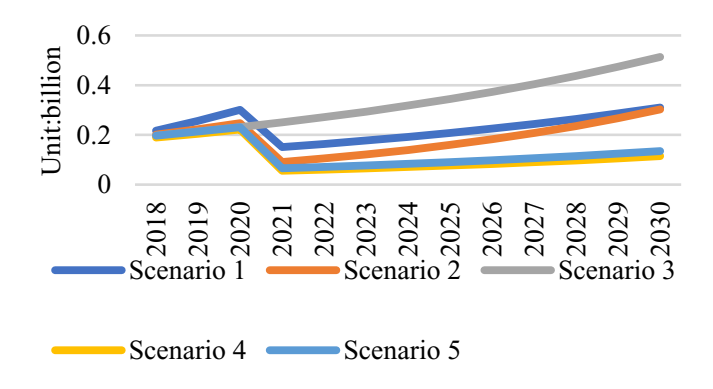

Figure 14. Changes in Output of Petroleum

\subsubsection{The impacts on fossil energy output}

The impacts of fiscal subsidy policies on the output of the fossil energy were shown in figure 12, figure 13 and figure 14. Through the omparison of scenario 1, 2 and 5 , we could see that amounts of subsidies directly affected the size of the increase in fossil output. The more subsidies scenario had, the greater the impact. And by 2030, the impact of scenario 1 reached the maximum. In addition, In the early period, scenario 1 and 2 change rapidly, but in the later period the situation was the opposite situation. On the tax side, the scenario with lower tax rate, the more the output it had. The lower tax rate of the new energy enterprises reduced the price of new energy power, and then reduced the production cost of the electricity use sectors, thus it stimulated the expansion of the economy scale. As the expansion of the economy was much more stimulating to the output of the coal sector, it was far greater than the inhibition effect of the new energy power generation enterprises. Natural gas showed an increasing state. The expansion of the economy stimulated the output of the coal sector, and this effect was far greater than the inhibition effect of new energy power generation enterprises. Therefore, coal, oil and petroleum all shown an increasing state under the preferential tax scenarios.

\section{Conclusions}

This paper used dynamic 3ED-CGE model to compare the economic impact of different new energy finance and taxation policies. According to the results of policy scenario simulations, the implementation of fiscal and taxation policies of new energy industries has some impacts on economic growth, welfare of residents, electricity output, and fossil energy output. In terms of financial subsidies, the implementation of the fiscal subsidy method with declining slope has a good effect on promoting GDP growth, increasing employment rate and improving the welfare of residents, but it cannot effectively promote the adjustment of energy demand structure. After 2020, the implementation of the parity scheme for wind power and solar photovoltaic power enterprises will not have a negative impact on the development of the economy and new energy industry. In terms of value added tax, after the expiry of the preferential tax policy for the development of the western region, the new energy plant can continue to be implemented the preferential tax policy with a duty rate of $15 \%$. In terms of income tax, $8.5 \%$ income tax rate has little difference from $6 \%$ income tax rate on GDP growth, employment increase and residents' welfare improvement, however, the effect of $6 \%$ of the income tax on the adjustment of the electricity demand structure is obviously better than that of $8.5 \%$.

\section{Acknowledgments}

This work is financially supported by the National Natural Science Foundation of China (71363037), Inner Mongolia Natural Science Foundation (2016MS0708), and Inner Mongolia Social Science Foundation(2015A010).

\section{References}

1. Y. Wang, N. Li, B. Yuan, F. Zhang, J. Feng.Discussion on the problem of "reasonable abandoning energy" in power system planning with large proportion of new energy sources [J]. China Electric Power Company, 50(11):8-14(2017)

2. Y. Ding, L. Xu. Research on fiscal and tax policy effects of China's new energy industry [J]. Economic Research Reference, 38: 33-48(2015)

3. Y. Yu. Subsidy demand and tax burden effect of China's wind and solar tariff policy $[\mathrm{J}]$. Finance and Trade Research, 3: 106-116(2016)

4. 4. H. He, D. Shi, S. Xu. Tax policy orientation to promote the development of low carbon economy and new energy industry $[\mathrm{J}]$. Tax Research, 9: 8-12(2012)

5. X. Wang, W. Cai, W. Tang. Research on the tax policy system of China's new energy industry [J]. Tax Research,5:11-15(2011)

6. Y. Wang. Development course and Countermeasure of renewable energy policy in China [C]. Renewable Energy Development and Utilization Seminar, 4:16-19(2008)

7. J. K. An. Integrated Time-depending Feasibility Analysis Model of Wind Energy Applications in Greece[J]. Energy Policy. 3:267-280(2002)

8. Q. Liu. Analysis of fiscal subsidy effect of new energy listed Companies in China [D]. Anhui University( 2013)

9. J. Ma. Research on fiscal and taxation policies to promote the development of clean energy in China [D]. China University of Geosciences (Beijing)(2015)

10. S. Yang. The economic impact and improvement direction of China's renewable energy subsidy policy: taking wind power as an example [J]. Journal of Yunnan University of Finance and 
Economics, 29 (2): 64-74(2013)

11. Y. Sun. Construction and application of CGE model for wind power industry policy analysis [D]. Nanjing University of Aeronautics \& Astronautics(2012)

12. D. Liu. Analysis of the impact of carbon tax policy on Inner Mongolia's economy and environment [D]. Inner Mongolia University of Technology(2013)

13. W. Liu, Z. Cai, Y. Guo. Research on the relationship between economic growth and employment in China at present stage $[\mathrm{J}]$. economic science, 04 : 5-17(2015)

14. J. Wu, J. Lin. Welfare transformation effect of economic growth: comparison between China and the world [J]. Quantitative Economic and Technical and Economic Research, 32 (08): 3-24(2015)

15. S. Ma. Effect of sulphur tax on sulfur dioxide emissions and energy consumption in China [J]. China Industrial Economy, 2: 20-30(2008)

16. F. Zhai, Thomas Warren Hertel. Impacts of the Doha development agenda on China: The role of labor markets and complementary education reforms[M].California: SSRN eLibrary(2005) 